\title{
POLíticAS PÚBlicAS PARA A fORMAÇÃo de PROFESSORES E CONTEXTOS EMERGENTES NA EDUCAÇÃO SUPERIOR
}

\begin{tabular}{c} 
PUBLIC POLICIES FOR TEACHER TRAINING AND \\
EMERGING CONTEXT IN HIGHER EDUCATION \\
\hline POLÍTICAS PÚBLICAS PARA LA FORMACIÓN DE PROFESORES \\
Y CONTEXTOS EMERGENTES EN LA EDUCACIÓN SUPERIOR \\
Marilene Gabriel Dalla Corte ${ }^{1}$ \\
Rosane Carneiro Sarturi $^{2}$
\end{tabular}

\section{RESUMO}

Este texto refere-se a políticas de formação de professores e a repercussão em contextos emergentes na educação superior, a partir do desenvolvimento de programas como o Programa de Bolsas de Iniciação à Docência (PIBID), Programa de Capacitação de Conselheiros Municipais de Educação (PRÓ-CONSELHO) e Observatório de Educação (OBEDUC). Objetiva-se, nesse sentido, analisar as políticas públicas de formação de professores (inicial e permanente), desenvolvidas pelo Centro de Educação da Universidade Federal de Santa Maria, e os contextos emergentes na educação superior. Trata-se de uma pesquisa de natureza qualitativa, a partir do estudo de caso, sendo que a análise de dados está embasada na coleta e construção de dados a partir de marcos regulatórios e relatórios alusivos a Programas de Governo já mencionados implementados pelo Centro de Educação da Universidade Federal de Santa Maria (CE/UFSM). Os estudos vem contribuindo para a compreensão das políticas públicas voltadas para a formação de professores (inicial/permanente) em íntima inter-relação com contextos emergentes na educação superior; o reconhecimento e a compreensão da cultura organizacional e dos processos de gestão dos programas analisados a partir das experiências desenvolvidas pelo CE/UFSM e sua repercussão na qualidade da formação inicial e permanente de professores; uma reflexão crítica acerca da compreensão e o envolvimento dos professores/gestores sobre contextos emergentes na educação superior.

PALAVRAS-CHAVE: Educação superior. Políticas públicas. Formação de professores. Contextos emergentes. Qualidade.

\begin{abstract}
This text refers to training policies for teachers and the rebound in emerging contexts in higher education, from the development of programs such as Fellowship Program Introduction to Teaching (PIBID) Training Program of Municipal Directors of Education (PRO -Board) and Centre of Education (OBEDUC). The objective is, in this sense, analyzing the policies of teacher training (initial and ongoing), developed by the Education Center of the Federal University of Santa Maria, and emerging contexts in higher education. It is a qualitative research from the case study, and the data analysis is grounded in the collection and building data from regulatory frameworks and allusive reports to Government programs already mentioned implemented by the Education Center the Federal University of Santa Maria (CE / UFSM). The study has contributed to the understanding of public policies for teacher training (initial / continuous) in close interrelation with emerging contexts in higher education; recognition and understanding of the organizational culture and management processes of the programs analyzed from the experiences developed by CE / UFSM and its impact on quality of initial and
\end{abstract}

\footnotetext{
1 Doutora em Educação. Professora Adjunta do Departamento de Administração Escolar, do Centro de Educação, da Universidade Federal de Santa Maria. Coordenadora Substituta do Programa de Pós-Graduação em Políticas Públicas e Gestão Educacional da PPPG/UFSM. Coordenadora Geral do Pró-Conselho - UFSM. E-mail: marilenedallacorte@gmail.com

2 Pós-Doutora em Educação. Professora Adjunta do Departamento de Administração Escolar, do Centro de Educação, da Universidade Federal de Santa Maria. Coordenadora do Programa de Pós-Graduação em Políticas Públicas e Gestão Educacional da PPPG/UFSM. E-mail: rcsarturi@gmail.com
}

Recebido em: 05/09/2015 - Aceito em: 02/12/2015.

\begin{tabular}{l|l|l|l|l|l|l} 
(C) Rev. Inter. Educ. Sup. & Campinas, SP & v.1 & n.2 & p.160-181 & out./dez. 2015 & ISSN 2446-9424
\end{tabular}


continuing teacher training; a critical reflection on the understanding and involvement of teachers / managers on emerging contexts in higher education.

KEYWORDS: Higher education. Public policy. Teacher training. Emerging contexts. Quality.

\section{RESUMEN}

Este texto se refiere a políticas de formación de profesores y la repercusión en contextos emergentes en la educación superior, a partir del desarrollo de programas como el Programa de Becas de Iniciación a la Docencia (PIBID), Programa de Capacitación de Consejeros Municipales de Educación (PRÓ-CONSELHO) y Observatorio de Educación (OBEDUC). Se objetiva, en ese sentido, analizar las políticas públicas de formación de profesores (inicial y permanente), desarrolladas por lo Centro de Educación de la Universidad Federal de Santa Maria, y los contextos emergentes en la educación superior. Se trata de una investigación de naturaleza cualitativa, a partir del estudio de caso, siendo que el análisis de datos se basa en la colecta y construcción de datos a partir de marcos regulatorios e informes alusivos a Programas de Gobierno ya mencionados implementados por el Centro de Educación de la Universidad Federal de Santa Maria (CE/UFSM). Los estudios vienen contribuyendo a la comprensión de las políticas públicas vueltas a la formación de profesores (inicial/permanente) en íntima interrelación con contextos emergentes en la educación superior; el reconocimiento y la comprensión de la cultura organizacional y de los procesos de gestión de los programas analizados a partir de las experiencias desarrolladas por lo CE/UFSM y su repercusión en la calidad de la formación inicial y permanente de profesores; una reflexión crítica acerca de la comprensión y el envolvimiento de los profesores/gestores sobre contextos emergentes en la educación superior.

PALABRAS CLAVE: Educación superior. Políticas públicas. Formación de profesores. Contextos emergentes. Calidad.

\section{INTRODUÇÃO}

Ao longo do século XX e início do século XXI, as políticas públicas para a educação básica e superior no Brasil passaram por [re]estruturações de pequenas a grandes proporções. Tais perspectivas imbricadas ao aumento populacional, ao desenvolvimento e o crescimento econômico no país, condicionados a fatores tais como urbanização, industrialização e formação tem sido preocupação constante nas pesquisas e debates, especialmente no que tange a universalização do acesso e aos aspectos constitutivos à formação e atuação docente de qualidade. Também, o processo de internacionalização das políticas educacionais e a realidade que envolve a formação e valorização de professores no Brasil estão intimamente interligados (AZEVEDO; CATANI, 2013).

Além da perspectiva normativa para atendimento as metas mundiais para a educação superior, outros marcos importantes foram delineando os encaminhamentos realizados pela União, para atender as especificidades e necessidades das redes e sistemas de ensino, articulando as Instituições de Ensino Superior, por adesão dos estados, municípios e Distrito Federal. Tais perspectivas implicaram no surgimento de uma nova conjuntura para a educação superior e, consequentemente, novas demandas para a universidade que, diretamente, influencia e se deixa influenciar pelo campo das políticas públicas educacionais no Brasil entre outras realidades mundiais. Essa realidade multifacetada passou denominar-se contexto emergente e requer uma nova pedagogia universitária.

Verifica-se a existência de um paradigma educacional que vem [re]articulando novos rumos e, consequentemente, novos processos de gestão de Cursos e Programas na Universidade. Para tanto, no redimensionamento desse cenário prioriza-se compreender quais as políticas e as ações desenvolvidas na interlocução entre educação superior e básica - no

\begin{tabular}{l|l|l|l|l|l|l|}
\hline (C) Rev. Inter. Educ. Sup. & Campinas, SP & v.1 & n.2 & p.160-181 & out./dez. 2015 & ISSN 2446-9424
\end{tabular}


âmbito global/nacional/local, sob o viés da qualidade da formação e atuação profissional, delineiam e desencadeiam contextos emergentes. Tais contextos precisam ser analisados e reflexionados em sua conjuntura e impactos, tornando-se cada vez mais importante discutir e delinear limites e possibilidades que poderão contribuir para que as políticas públicas e programas/ações subjacentes à formação de professores (inicial e permanente) sejam [re]pensadas, [re]significadas e implementadas de maneira articulada e compartilhada, no sentido de [co]responsabilidade entre os envolvidos. Sobretudo, que tais políticas potencializem melhorias na formação e repercutam na produção e atuação docente de qualidade, não se esvaziando em si mesmas.

Nessa lógica, cabe destacar que o interesse pela temática de pesquisa surgiu a partir das experiências das pesquisadoras em cursos de licenciatura e de pós-graduação que estão intimamente inter-relacionados a contextos emergentes, para efeito deste estudo serão destacados três programas entre os propostos pelo governo federal, que estão sendo desenvolvidos pelo Centro de Educação (CE) da Universidade Federal de Santa Maria (UFSM): Programa Institucional de Bolsa de Iniciação à Docência (PIBID), Programa de Capacitação de Conselheiros Municipais de Educação (PRÓ-CONSELHO) e Observatório de Educação (OBEDUC) da Coordenação de Aperfeiçoamento de Nível Superior (CAPES).

Assim sendo, objetiva-se analisar as políticas públicas de formação de professores (inicial e permanente), desenvolvidas pelo Centro de Educação da Universidade Federal de Santa Maria, e os contextos emergentes na educação superior. Busca-se, portanto, reconhecer e reflexionar as políticas de formação de professores em contextos emergentes, a partir de um estudo do caso do Centro de Educação da Universidade Federal de Santa Maria, o que contribui, especialmente, para o próprio Centro de Ensino de uma universidade pública passar a refletir acerca dos seus processos de gestão administrativo-pedagógica em interlocução com as políticas educacionais vigentes, bem como desenvolver e socializar o conhecimento sobre educação superior nos níveis institucional, nacional e internacional.

O delineamento metodológico ancora-se na abordagem qualitativa e no estudo de caso. Essa abordagem de pesquisa expressa uma configuração analítica e qualitativa do fenômeno investigado; é perceptível principalmente quando o lócus de pesquisa é o cenário educacional e essa relação está intrinsicamente constituída no fenômeno pesquisado (TRIVINOS, 2008), visto que ao pesquisar no âmbito dos programas de governo desenvolvidos pelo Centro de Educação da UFSM e sua correlação com contextos emergentes, se está trabalhando com dados que viabilizam o processo investigativo.

A metodologia qualitativa, como referencial de investigação, está fundada no estudo de caso, justamente porque se trata de uma pesquisa conectada a uma universidade pública e seus alguns programas de governo que estão diretamente relacionados à formação inicial e continuada de professores o que, eminentemente constitui como modalidade do fazer investigativo, delimitando os contexto macro e micro, tornando representativo de uma prática estudada. André (1995, p. 31) coloca que:

\begin{tabular}{l|l|l|l|l|l|l} 
(C) Rev. Inter. Educ. Sup. & Campinas, SP & v.1 & n.2 & p.160-181 & out./dez. 2015 & ISSN 2446-9424
\end{tabular}


[...] o estudo de caso enfatiza o conhecimento particular. O interesse do pesquisador ao selecionar uma determinada unidade é compreendê-la como uma unidade. Isso, não impede, no entanto, que ele esteja atento ao seu contexto e às suas interrelações como um todo orgânico, e à dinâmica como um processo, uma unidade em ação.

Segundo Yin (2005) o estudo de caso é utilizado para contribuir com o conhecimento dos fenômenos individuais, organizacionais, sociais, políticos e de grupo, além de outros fenômenos relacionados a estes. Porém, não se priorizou focar modificações a real situação do contexto, mas, sobretudo, compreender essas situações contextuais e estabelecer profundidade analítica a partir de questionamentos, confrontações e inter-relações com dados já existentes, ampliando-os para constituir, sobretudo um olhar crítico-reflexivo acerca da problemática de pesquisa. $O$ processo de construção de dados tem por base a análise de marcos regulatórios de tais políticas públicas educacionais, bem como relatórios alusivos a Programas de Governo (PIBID, OBEDUC e PRÓ-CONSELHO), que traduzem ações de ensino, pesquisa e extensão implementados pelo Centro de Educação da Universidade Federal de Santa Maria.

Para tanto, o campo teórico-prático, decorrente desta pesquisa, congrega com as atividades de ensino, pesquisa e extensão, bem como os estudos que vem sendo produzidos pelo Grupo de Estudos e Pesquisas ELOS e pelo GESTAR - Grupo de Estudos e Pesquisas em Políticas Públicas e Gestão Educacional, o que, sobremaneira, alimenta e consolida uma rede acadêmica e a interlocução entre pares que tem em comum a área de conhecimento da educação superior. Também, destaca-se que tais discussões poderão alicerçar e constituir potencial de [re]significação e [re]articulação das políticas públicas nacionais e locais voltadas para a formação de professores (inicial e continuada) em sinergia com contextos emergentes, ainda mais considerando o advento da atual Resolução CNE n. ${ }^{\circ}$ 2/2015 (BRASIL, 2015) a qual postula Diretrizes Curriculares Nacionais para a formação inicial em nível superior (cursos de licenciatura, cursos de formação pedagógica para graduados e cursos de segunda licenciatura) e para a formação continuada de professores no Brasil.

\section{EDUCAÇÃO SUPERIOR E CONTEXTOS EMERGENTES}

A partir da década de 90 o cenário da internacionalização do ensino superior denota o cerceamento da globalização no ensino de graduação e pós-graduação. Surgem, concepções da Organização das Nações Unidas para a Educação, a Ciência e a Cultura (UNESCO) acerca da "Educação no século XXI", em que são repensadas e [re]articuladas questões como equidade e qualidade da educação no mundo, as missões e abrangência da universidade, concepção de educação superior promulgada pelo Banco Mundial e o Fundo Monetário Internacional. Morosini (2005) coloca que o Brasil sofre diretamente essas influências, principalmente junto aos movimentos voltados para a estruturação de uma universidade pública e democrática. 
A Declaração Mundial $^{3}$ (1998) estabeleceu missão e funções para a educação superior e, entre elas, destaca-se: igualdade de acesso; fortalecimento da participação e promoção do acesso; reforçar a cooperação com o mundo do trabalho, analisar e prevenir as necessidades da sociedade; diversificação como forma de ampliar a igualdade de oportunidades; aproximações educacionais inovadoras; avaliação da qualidade; o potencial e o desafio de tecnologia; compartilhar conhecimentos teóricos e práticos entre países e continentes; parcerias e alianças. Tais pressupostos passaram a demarcar a expansão e as múltiplas interfaces da educação superior no século XXI.

Morosini (2014, p. 387) aponta que a educação superior “[...] vive um momento singular no contexto sócio-histórico e econômico mundial". Além disso, e dos desafios às funções de ensino, pesquisa e extensão de qualidade, e com base nas reflexões sobre "mutação" de Didriksson (2008), a autora se refere a novos desafios que é preciso considerar as demandas locais num contexto global. Pois:

\begin{abstract}
Esse estado de mutação traz consigo Contextos Emergentes da Educação Superior: configurações em construção na educação superior observadas em sociedades contemporâneas e que convivem em tensão com concepções pré-existentes, refletoras de tendências históricas. (RIES, 2013). São contextos que tem o ethos do desenvolvimento humano e social na globalização, em que há interação com outras formas de contextos. (MOROSINI, 2014, p. 387)
\end{abstract}

Cabe destacar que no Brasil, além do envolvimento de órgãos e instituições internacionais como a $\mathrm{UNESCO}^{4}$, $\mathrm{IESALC}^{5}, \mathrm{OECD}^{6}, \mathrm{GUNI}^{7}$, entre outros que estão empenhados em questões e ações que priorizam a universidade socialmente responsável e emancipatória, as ações governamentais, de maneira direta, desencadeiam contextos emergentes inter-relacionados à comunidade universitária.

Castro (1999) se refere a políticas de expansão e melhoria do ensino superior tendo por base a reorganização do sistema de ensino superior pelo Decreto n ${ }^{\circ}$ 2.306/97 (BRASIL, 1997), baseadas nos princípios estabelecidos pela Lei de Diretrizes de Bases da Educação Nacional - LDB, Lei n. ${ }^{\circ}$ 9.394/96 (BRASIL, 1996), que priorizam, entre outras medidas: a) a diversificação institucional a partir da criação de novas modalidades jurídicas dos Centros

\footnotetext{
3 Disponível em: <http://www.scribd.com/doc/9715944/Declaracao-Mundial-Sobre-Educacao-Superior-NoSeculo-XXI>.

4 A Organização das Nações Unidas para a Educação, a Ciência e a Cultura - UNESCO, organismo internacional que objetiva contribuir com ações educacionais mundo inteiro, no sentido de veicular paz e segurança aos cidadãos. Voltada para a minimização do analfabetismo no mundo, prioriza essencialmente a formação e qualificação de professores.

${ }^{5}$ O Instituto Internacional para a Educação Superior na América Latina e no Caribe - IESALC é um organismo agregado à UNESCO, voltado à promoção do acesso e da qualidade na educação superior.

${ }^{6}$ A Organização para a Cooperação Econômica e Desenvolvimento, em sua representatividade, tem 30 países agregados e envolvidos com o desenvolvimento econômico, com a sustentabilidade, com alternativas de geração de novos empregos, aumento da qualidade de vida, assim como contribuir para o crescimento do comércio mundial.

${ }^{7}$ Global University Network for Innovation (GUNI). Organizou a $4^{\text {a }}$ Conferência Internacional de Barcelona sobre o Ensino Superior, intitulada "Novos Desafios e emergentes funções para o desenvolvimento humano e social. Foi realizada em Barcelona, de março a abril de 2008.
}

\begin{tabular}{l|l|l|l|l|l|l} 
(C) Rev. Inter. Educ. Sup. & Campinas, SP & v.1 & n.2 & p.160-181 & out./dez. 2015 & ISSN 2446-9424
\end{tabular} 
Universitários e das Faculdades Integradas; b) expansão de vagas; c) implantação do Sistema Nacional de Avaliação da Educação Superior (SINAES); d) verificação das condições de oferta de cursos e vagas; e) elaboração das novas Diretrizes Gerais dos Currículos de Graduação com base em expansão e melhoria na oferta de cursos, ampliação e integração entre as várias áreas do conhecimento, flexibilização curricular e modalidade de ensino; e) combate à evasão e ampliação do espaço de decisão do aluno na definição do seu currículo acadêmico; f) incentivo à titulação docente, mediante continuidade dos programas de apoio à qualificação do magistério para o ensino superior; g) recuperação e melhoria da infraestrutura das Instituições Federais de Ensino Superior (IFES) e; h) sistema de avaliação da pósgraduação, estimulando a sua melhoria e expansão.

Para Ferreira e Oliveira (2010, p. 53-54):

\begin{abstract}
De maneira geral, diferentes países vêm adotando uma nova regulação transnacional para a educação superior, traduzida em políticas, projetos e ações. Nessa direção, busca-se: a) maior articulação entre os sistemas educativos e o setor produtivo; b) expansão e absorção de um número crescente de alunos; c) racionalização na utilização dos recursos públicos e prestação de contas (acountability), conjugadas com autonomia e programa de avaliação centrada nos resultados; d) adoção de gestão estratégica e de gestores empreendedores para as universidades; e) diferenciação das Instituições de Ensino Superior (IES), dos programas e dos cursos, bem como maior regionalização e atendimento ao meio econômico e social em que as instituições estão inseridas; f) diversificação das fontes de financiamento; g) expansão de cursos e vagas via crescimento de IES privadas; h) reorganização e flexibilização curricular, tendo em vista a adoção dos chamados currículos por competências; i) criação de novas modalidades e tipos de cursos, em face dos novos nichos e demandas do mercado.
\end{abstract}

No que diz respeito à função do Estado e sua relação com qualidade da educação superior, as reformas presentes no campo educacional passaram a caracterizarem-se, cada vez mais, pelo alinhamento as políticas mundiais de educação, bem como pela regulação e implementação de ações estatais que, sob o viés da qualidade, postulam melhorias que estão regulamentadas por dispositivos de expansão, diversificação e avaliação e, sobretudo, regulação do Ministério da Educação (MEC). No Brasil, portanto, as políticas de formação docente tem buscado aderência às exigências mundiais e a formação inicial e permanente estão na centralidade dos processos que envolvem a profissionalização dos docentes. Tais políticas têm sido consideradas como requisito mínimo para a valorização docente.

A exemplo do que dimensionam Ferreira e Oliveira (2010) quando se referem a "[...] regulação transnacional para a educação superior, traduzida em políticas, projetos e ações”, elucida-se de maneira geral algumas ações e programas nessa conjuntura:

a) o surgimento da Rede Nacional de Formação Continuada de Professores em 2004, com ampla finalidade de articulação da formação continuada à pesquisa e, consequentemente, à produção acadêmica desenvolvida nas Universidades;

b) o Pró-Licenciatura, criado em 2005, voltado para a formação inicial a distância de professores em serviço; 
c) a criação da Universidade Aberta do Brasil (UAB) ${ }^{8}$ pelo Decreto n. ${ }^{\circ}$ 5.622/2005 (BRASIL, 2005), sendo que os cursos nesta modalidade educativa passaram a equiparar-se aos cursos presenciais e a prioridade de atendimento da UAB, na perspectiva da formação de professores, esteve e está voltada aos docentes atuantes na educação básica, assim como as equipes diretivas, dirigentes municipais, conselheiros, entre outros sujeitos que atuam na educação básica; tais programas/cursos tem relação direta com a formação inicial e continuada dos profissionais da educação;

d) o Prodocência, com o objetivo de fomentar e estimular o desenvolvimento de projetos institucionais voltados para a gestão educacional/escolar, experiências metodológicas e práticas inovadoras, cooperação técnica entre a universidade e demais contextos educativos (escolares e não escolares);

e) o Decreto $n^{\circ}$. 6.096/2007 (BRASIL, 2007), instituindo o Programa de Apoio a Planos de Reestruturação e Expansão das Universidades Federais (REUNI);

f) além das Diretrizes Curriculares Nacionais para a Formação de Professores da Educação Básica no Brasil, instituída pela Resolução CNE n 1/2002 (BRASIL, 2002), na perspectiva do Decreto n. ${ }^{\circ}$ 6.775/2009 (BRASIL, 2009), foi instituída a Política Nacional de Formação de Profissionais do Magistério da Educação Básica disciplinando a atuação da Coordenação de Aperfeiçoamento de Pessoal de Nível Superior (CAPES) no fomento a programas de formação inicial e permanente para, entre outras perspectivas, potencializar o desenvolvimento dos professores, suas necessidades, potencialidades e disponibilidades, bem como garantir a qualidade dos espaços coletivos de formação;

g) ações de formação inicial e permanente, mediatizadas pelas universidades, com auxílio a projetos relativos às ações de formação com o apoio financeiro aos Estados, Municípios e Distrito Federal, em regime de cooperação técnica, para implementação de programas, projetos e cursos de formação a exemplo de Programas e Ações: Programa Institucional de Bolsa de Iniciação à Docência (PIBID); Observatório da Educação; formação superior de professores $-1^{\mathrm{a}}$ ou $2^{\mathrm{a}}$ licenciaturas, formação pedagógica para professores com graduação sem licenciatura, formação pedagógica para bacharéis; Cursos de Especialização (presencial, semipresencial e a distância); Mestrados Profissionais para os profissionais da educação em serviço; Redes de capacitação e formação continuada - Pró-Infantil; Educação Inclusiva Direito à Diversidade; Pacto Nacional pela Idade Certa; Pacto Nacional do Ensino Médio; Pró-Conselho; Pradime; Formação de Conselheiros Escolares; Programa Escola Ativa, entre outros.

\footnotetext{
${ }^{8}$ O Sistema UAB foi criado pelo Ministério da Educação no ano de 2005. Trata-se de uma política pública de articulação entre a Secretaria de Educação a Distância (SEED/MEC) e a Diretoria de Educação a Distância (DED/CAPES) com vistas à expansão da educação superior, no âmbito do Plano de Desenvolvimento da Educação (PDE). Sustenta-se em cinco eixos fundamentais: expansão pública da educação superior; aperfeiçoamento dos processos de gestão das instituições de ensino superior; avaliação da educação superior a distância; estímulo à investigação em educação superior a distância no País; financiamento dos processos de implantação, execução e formação de recursos humanos em educação superior a distância. Disponível em: <http://www.uab.capes.gov.br/index.php?option=com_content\&view=article\&id=9\&Itemid=21>.
}

\begin{tabular}{l|l|l|l|l|l|l} 
(C) Rev. Inter. Educ. Sup. & Campinas, SP & v.1 & n.2 & p.160-181 & out./dez. 2015 & ISSN 2446-9424 \\
\hline
\end{tabular}


De maneira elucidativa, a Educação Superior no Brasil vem vivendo intenso e diversificado processo de [re]significação e, nesse sentido, “[...] a universidade relevante passa a ser aquela que assume uma perspectiva mais utilitarista, empreendedora, flexível e inovadora e que, além disso, forma para as competências requeridas e alteradas permanentemente pelo mercado de trabalho" (FERREIRA; OLIVEIRA, 2010, p. 52). Nesse novo cenário: "As universidades têm sido levadas a abandonar, em grande parte, seu tradicional papel na construção do conhecimento e da formação como bens públicos para adotar o mercado como referência de sua produção e de sua gestão" (FERREIRA; OLIVEIRA, 2010, p. 53), passando a aderir e propor novos projetos e programas, a partir da consolidação de parcerias, nas quais estão os contextos das redes de ensino, o Sistema UAB, programas de governo mobilizados pelo tripé ensino-pesquisa-extensão, inclusive edificados pelo REUNI. Participando desse movimento [inter]nacional, a universidade tem o desafio de inserir-se numa lógica global para além dos seus muros. Pois:

[...] os contextos emergentes são caracterizados por: sistema de educação superior complexo, heterogêneo, segmentado socialmente; Sistema de Educação Superior em expansão e interiorizado; Macro Universidades; Multicampos de estruturas diferenciadas; Institutos Tecnológicos Fundamental, Médio, Médio Superior e Superior; Concentração da Empresa Privada no acesso social e no número de instituições; Investigação com multiplicidade de laboratórios e institutos de ciência que abarcam todas as áreas de pensamento humano e suas fronteiras; Massificação da demanda social por educação superior e uma forte presença da internacionalização. [...] No Brasil, além de muitas especificidades acima apontadas, o contexto de transição, na educação superior, está sendo marcado pela expansão acelerada, por políticas de diversificação, pela privatização e por tendências democratizantes, comandadas pela centralização estatal [...]. (MOROSINI, 2014, p. 388-389)

O que se verifica na atualidade é um contexto engendrado de múltiplas incoerências, problemáticas sociais e econômicas que desencadeiam desigualdades inclusive educacionais, problemas multifacetados que estão relacionados a opções e ações político-pedagógicas institucionais. Nessa conjuntura, as Instituições de Educação Superior são desafiadas a compreender essa lógica mundial/nacional/local e oportunizar espaços de discussão, estudo e interação entre sujeitos, estudos de marcos legais e teóricos, estudo e análises conjunturais de indicadores e de fatores intervenientes a atuação docente na sociedade do conhecimento e que produz e é produzida por contextos emergentes.

Scheibe e Bazzo (2013, p.18) se referem a transformação do funcionamento do sistema educativo de maneira dinâmica e, embasadas em Barroso (2005), afirmam que tal perspectiva "[...] emana da diversidade de fontes e de fluxos de regulação que se fazem presentes em dado contexto histórico e político". As autoras também mencionam:

A função fiscalizadora e reguladora do Estado necessita de reajustes ante a realidade apresentada, por meio de um sistema mais vigoroso de acompanhamento e discussão do que ocorre nas instituições formadoras. Nesse sentido, os currículos de formação precisam ser mais bem equacionados (Idem, p. 31). 
O debate e a interlocução [inter]institucional, certamente, oportuniza e fortalece a conscientização, a [re]significação e a [re]organização de propostas curriculares dos cursos de licenciatura, tendo por base a compreensão desse paradigma emergente que tem versado políticas públicas de formação a partir de novos formatos e ações [inter]nacionais e, consequentemente, [inter]institucionais.

Para Scheibe e Bazzo (2013, p. 32):

[...] parece imperativo continuar buscando estratégias e definições políticas que reforcem institucionalmente os cursos de Licenciatura, tarefa urgente para pesquisadores e formuladores de políticas públicas, os quais para responder ao desafio já não poderão se furtar da análise do conteúdo dos projetos pedagógicos implantados a partir das orientações emanadas das DCNs. É necessário ampliar os estudos e as investigações que envolvam não apenas o exame crítico das proposições discursivas dos projetos, mas também das práticas curriculares desenvolvidas nos diferentes cursos de Licenciatura oferecidos pelas IES do país.

A formação inicial de professores tem relevância ímpar na conjuntura das políticas de formação docente no Brasil, uma vez que dela desencadeiam-se as bases fundantes subjacentes à atuação do profissional da educação. É nestas bases que o profissional vai, primeiramente, buscar subsídios para exercer a atividade educativa nos múltiplos contextos de atuação docente, os quais repercutem no seu desenvolvimento profissional.

\section{UM OLHAR NOS PROGRAMAS DE FORMAÇÃO DE PROFESSORES DESENVOLVIDOS PELO CENTRO DE EDUCAÇÃO - UFSM}

\section{Programa Institucional de Bolsas de Iniciação à Docência}

O Programa Institucional de Bolsas de Iniciação à Docência foi implantado no Brasil em 2007, a partir da necessidade de formação de professores para atuar na educação e desta formação estar articulada com a educação básica; o programa acaba sendo levado para discussão a partir da Lei de Diretrizes e Bases da Educação Nacional - LDB de 1996. (GOMES E FELÍCIO, 2012).

No decorrer das atualizações da LDB/96, em 2013 o PIBID passa a ser inserido como uma política pública responsável por incentivar a formação de professores, como apresenta o Artigo 61, inciso V, da LDB, que se refere a cooperação técnica entre União, Distrito Federal, Estados e Municípios:

[...] incentivarão a formação de profissionais do magistério para atuar na educação básica pública mediante programa institucional de bolsa de iniciação à docência a estudantes matriculados em cursos de licenciatura, de graduação plena, nas instituições de educação superior. (BRASIL, 1996)

Assim, o Programa tem mais força e consegue ao decorrer de sua existência crescer com qualidade nas universidades e institutos de nível superior qualificando a formação de 
acadêmicos de licenciatura e todos os envolvidos para a realização do programa nas escolas.

Partindo das mudanças propostas pela LDB/96 surge as Diretrizes Curriculares Nacionais para a Formação de Professores da Educação Básica, em nível superior, curso de licenciatura, de graduação plena, com a relevância para a docência como base de formação, relacionando teoria e prática e criando vínculos com as instituições formadoras e a educação básica, para qualificar a formação:

\begin{abstract}
Mas há dois aspectos no Art. 61 que precisam ser destacados: a relação entre teoria e prática e o aproveitamento da experiência anterior. Aprendizagens significativas, que remetem continuamente o conhecimento à realidade prática do aluno e às suas experiências, constituem fundamentos da educação básica, expostos nos artigos citados. Importa que constituam, também, fundamentos que presidirão os currículos de formação e continuada de professores. Para construir junto com os seus futuros alunos experiências significativas e ensiná-los a relacionar teoria e prática é preciso que a formação de professores seja orientada por situações equivalentes de ensino e de aprendizagem. (BRASIL, 2001)
\end{abstract}

Com isso, em 2007 o Ministério da Educação resolve instituir o Programa Institucional de Bolsas de Iniciação à Docência, com o objetivo de oportunizar experiências correlacionadas à realidades escolares nas quais os acadêmicos viriam a desenvolver suas práticas docentes e de alguma forma contribuísse com aprendizagens significativas:

\footnotetext{
Instituir, no âmbito do Ministério da Educação, da Fundação Coordenação de Aperfeiçoamento de Pessoal de Nível Superior - CAPES e do Fundo Nacional de Desenvolvimento da Educação - FNDE, o Programa de Bolsa Institucional de Iniciação à Docência - PIBID, com vistas a fomentar a iniciação à docência de estudantes das instituições federais de educação superior e preparar a formação de docentes em nível superior, em curso presencial de licenciatura de graduação plena, para atuar na educação básica pública. (BRASIL, 2007)
}

O primeiro Edital do Programa PIBID, lançado pelo Ministério da Educação e fomentado pela CAPES e Fundo Nacional de Desenvolvimento da Educação (FNDE) em 2007, teve como uma das prioridades a valorização do magistério para incentivar os estudantes a optarem pela carreira docente, entre outros objetivos como a prática dos envolvidos, pensando na articulação entre teoria apresentada na formação acadêmica e a prática realizada nas escolas de educação básica, desenvolvidas pelo programa, e proporcionar o contato de acadêmicos com a realidade encontrada nas escolas de educação básica da rede pública. Assim, para fazer parte do Edital as instituições deveriam escrever um projeto institucional encaminhado a CAPES que após aprovação possibilitaria que os cursos de licenciatura desenvolvessem os seus subprojetos, englobando o objetivo do programa e do projeto da instituição.

No primeiro edital 2007, também ficou acertado a organização de bolsistas para atuarem no programa: um coordenador institucional, responsável pela coordenação geral e a equipe dos subprojetos, formada por: coordenadores da área, no caso, professor do curso do subprojeto, responsável por dar apoio aos bolsistas, supervisores das escolas e desenvolver e construir as práticas a serem desenvolvidas nas escolas pelo PIBID; supervisores que são

\begin{tabular}{l|l|l|l|l|l|l} 
(C) Rev. Inter. Educ. Sup. & Campinas, SP & v.1 & n.2 & p.160-181 & out./dez. 2015 & ISSN 2446-9424
\end{tabular}


professores da Educação Básica, que recebem os acadêmicos nas escolas para dar apoio na formação e nos desenvolvimentos das atividades, sendo um supervisor por escola para cada subprojeto; estudantes de iniciação à docência, ao qual diferentes formas de organização e quantidade estão atrelados, pois o edital estipulava um número máximo de 30 bolsistas por subprojeto. (BRASIL, 2007).

Em 2010, a Presidência da República com o Decreto $\mathrm{n}^{\mathrm{o}} 7.219$, de 24 de junho (BRASIL, 2010) teve a finalidade de qualificar a formação docente em nível superior e apresentar melhorias para a qualidade da educação básica pública brasileira. Ainda pelo Decreto ${ }^{\circ}$ 7.219/2010, se elenca no Artigo $3^{\circ}$ os objetivos do programa, todos tem por meta a intenção de qualificar a formação docente:

\begin{abstract}
Incentivar a formação de docentes em nível superior para a educação básica; contribuir para a valorização do magistério; elevar a qualidade da formação inicial de professores nos cursos de licenciatura, promovendo a integração entre educação superior e educação básica; Inserir os licenciandos no cotidiano de escolas da rede pública de educação, proporcionando-lhes oportunidades de criação e participação em experiências metodológicas, tecnológicas e práticas docentes de caráter inovador e interdisciplinar que busquem a superação de problemas identificados no processo de ensino-aprendizagem; incentivar escolas públicas de educação básica, mobilizando seus professores como coformadores dos futuros docentes e tornandoas protagonistas nos processos de formação inicial para o magistério; e contribuir para a articulação entre teoria e prática necessárias à formação dos docentes, elevando a qualidade das ações acadêmicas nos cursos de licenciatura. (BRASIL, 2010)
\end{abstract}

Durante este período de 2007 a 2015, o PIBID lançou seis editais, todos com alterações nas normas de implementação. Como apresenta os estudos de Tomazetti e Lopes (2013), o PIBID Diversidade que engloba a educação do campo e educação indígena, e a ampliação do programa para instituições públicas federais, estaduais, filantrópicas e comunitárias. O edital 001/2011/CAPES foi de grande importância para a melhoria da gestão do programa, quando se inovou incluindo um coordenador de área de gestão de processos educacionais, para apoiar a coordenação geral das instituições. (TOMAZETTI; LOPES, 2013).

Atualmente o PIBID é normatizado pela Portaria $\mathrm{n}^{\circ}$ 096, de 18 de Julho de 2013, criada considerando a necessidade de aperfeiçoar e atualizar as normas do programa, este documento contém esclarecimentos que apresentam os objetivos e requisitos para seleção de bolsistas e recomendações sobre escolas da rede pública a serem inseridas, considerando o Índice de Desenvolvimento da Educação Básica - IDEB abaixo da média nacional, e naquelas que tem experiências bem sucedidas de ensino e aprendizagem para perceber as diferenças entre as realidades das escolas, conforme o Artigo $8^{\circ}$ da Portaria $n^{\circ}$ 096/2013/PIBID/CAPES. (BRASIL, 2013)

O custeio das atividades desenvolvidas pelos subprojetos é financiado pela CAPES. O pedido de recursos é realizado durante a inscrição do subprojeto, são previstos auxílios para, materiais pedagógicos utilizados nas atividades nas escolas, viagens de estudos, pagamento

\begin{tabular}{l|l|l|l|l|l|l} 
(C) Rev. Inter. Educ. Sup. & Campinas, SP & v.1 & n.2 & p.160-181 & out./dez. 2015 & ISSN 2446-9424 \\
\hline
\end{tabular}


de passagem, alimentação e hospedagem para apresentação de trabalhos dos bolsistas e recursos para palestrantes de eventos do PIBID.

Ao referir o programa PIBID, consequentemente estamos nos referindo a um Programa de Ensino, no qual os acadêmicos não são obrigados a participar. Os acadêmicos possuem a autonomia de escolher fazer parte destas atividades extra curriculares de graduação. Consequentemente estará contribuindo para a sua formação inicial, uma vez que os objetivos do programa estão voltados para tal.

A Universidade Federal de Santa Maria - UFSM faz parte do Programa Institucional de Bolsas de Iniciação à Docência desde o primeiro edital da CAPES em 2007, e as atividades nas escolas começaram a partir de 2009, sendo que os primeiros cursos participantes foram de Biologia, Ciências, Física, Matemática e Química. (TOMAZETTI; LOPES, 2013).

O segundo edital aberto em 2009 proporcionou a participação de outros cursos como Artes Visuais, Educação Física, Filosofia, História e Pedagogia. O número de bolsistas do segundo edital foi cento e oito estudantes de licenciaturas, doze supervisores e cinco coordenadores de área, contemplando a participação de nove escolas da rede pública de ensino, estas informações são encontradas no livro publicado pelo PIBID - UFSM, em 2013. (TOMAZETTI; LOPES, 2013).

Os subprojetos do PIBID/2009 foram prorrogados através de Edital que a CAPES lançou em 2012, conforme sinalizam Tomazetti e Lopes (2013):

\begin{abstract}
Em março de 2012, a CAPES lançou o Edital CAPES nº 011/2012 para a submissão de propostas de novos projetos para instituições que ainda não tinham programa e ampliação dos que já existiam, permitindo a prorrogação dos projetos vinculados ao PIBID/2009 até 31 de julho de 2013. Além disso permitiu a inclusão de um coordenador de área de gestão de processos educacionais. (p. 20)
\end{abstract}

Todos os Subprojetos PIBID da UFSM encerraram suas atividades em 2013 e com a CAPES lançando o Edital $n^{\circ} 061 / 2013$ proporcionou ao projeto institucional e subprojetos das áreas concorrerem ao um novo edital que iniciou suas atividades nas escolas no início do ano de 2014.

Segundo as informações fornecidas pelo Coordenador Institucional do PIBID, na UFSM, professor Ricardo Fajardo, o Edital PIBID 2013 na Universidade Federal de Santa Maria contou com um grande número de bolsistas, organizados da seguinte forma: um coordenador geral, quatro (4) coordenadores de gestão de processos educacionais, e a participação de dezenove (19) subprojetos diferentes, totalizando trinta e três (33) coordenadores de área, setenta e dois (72) supervisores de escolas e quatrocentos e oito (408) bolsistas de iniciação à docência. Este grande grupo de bolsistas dos subprojetos PIBID/UFSM, possibilitam um grande impacto nas escolas da rede pública de ensino de Santa Maria, atingindo muitas áreas de ensino.

\begin{tabular}{l|l|l|l|l|l|l} 
(C) Rev. Inter. Educ. Sup. & Campinas, SP & v.1 & n.2 & p.160-181 & out./dez. 2015 & ISSN 2446-9424 \\
\hline
\end{tabular}


O programa PIBID na Universidade Federal de Santa Maria proporciona a participação de vários cursos de licenciatura, e possibilita a inserção de alunos de iniciação à docência em escolas da rede pública de ensino de Santa Maria-RS. A partir disso, o subprojeto PIBID Pedagogia/Anos Iniciais tem buscado selecionar escolas em que o Índice de Desenvolvimento da Educação Básica - IDEB esteja abaixo da média nacional e proporcionar aos seus bolsistas experiências de práticas pedagógicas e observações acerca das realidades escolares.

O Subprojeto PIBID/Pedagogia, iniciou a participação no projeto institucional a partir do Edital 2009, desenvolvendo suas atividades com vinte e quatro estudantes de iniciação à docência, três supervisoras de escolas de educação básica, e uma coordenadora de área. Em 2011, completavam-se dois anos de atividades do Edital PIBID/2009, neste momento, surge a oportunidade de prorrogação do edital, para mais dois anos de atividades, desta forma o subprojeto PIBID/Pedagogia conseguiu dar continuidade as suas ações. Ao final do ano de 2013 as práticas do subprojeto PIBID/Pedagogia edital PIBID/2009 estavam sendo encerradas, porém com a realização de um novo edital lançado pela CAPES e com a aprovação do projeto PIBID institucional, o subprojeto PIBID/Pedagogia concorreu novamente a bolsas, tendo a aprovação do projeto houve a continuidade das ações.

Com o novo Edital PIBID/2013 o subprojeto PIBID/Pedagogia/UFSM sofreu algumas alterações quando ao número de bolsistas e formas de organização. A partir do Edital 2013 o subprojeto passou a contar com trinta e seis (36) bolsistas de iniciação à docência, acadêmicos de Pedagogia, duas coordenadoras de área, professoras do curso de Pedagogia, e sete (7) professoras supervisoras da rede de ensino de educação básica, em que estes foram organizados em dois grupos, considerando as divisões das áreas de atuação dentro da Pedagogia, sendo um grupo constituído de vinte bolsistas de iniciação à docência, uma coordenadora de área e três supervisoras de escola para a etapa dos Anos Iniciais e o outro grupo constituído de dezesseis bolsistas de iniciação à docência, uma coordenadora de área e quatro supervisoras de escolas, para a etapa da Educação Infantil, oportunizando a escolha de duas experiências distintas aos acadêmicos de Pedagogia da Universidade Federal de Santa Maria.

Durante o período das ações do subprojeto PIBID/Pedagogia, os bolsistas foram deixando o subprojeto, dando a oportunidade de novos bolsistas ingressarem no programa, partindo disto pode-se afirmar que a partir das pesquisas realizadas com os egressos do subprojeto, mais de 100 bolsistas, a participação no subprojeto foi fundamental para a sua formação inicial e para as práticas desenvolvidas como profissionais, hoje com mais de $40 \%$ dos ex-bolsistas atuando como docentes na educação básica e os demais em processo de formação continuada, nos cursos de especialização e mestrado.

Acredita-se que os objetivos do subprojeto estão sendo atingidos, uma vez que os impactos das atividades desenvolvidas têm contribuído para a formação inicial dos acadêmicos, bem como o fortalecimento das relações entre a educação básica e superior.

\begin{tabular}{l|l|l|l|l|l|l} 
(C) Rev. Inter. Educ. Sup. & Campinas, SP & v.1 & n.2 & p.160-181 & out./dez. 2015 & ISSN 2446-9424
\end{tabular}


Nessa perspectiva é possível afirmar que os acadêmicos que participaram e participam do PIBID tem desenvolvido atividades que transcendem a mera regência de classe, estão articulados no contexto da escola, inserem-se nas comunidades escolares e compreendem o significado do papel social do professor. A Universidade passou, nesta perspectiva, a contribuir para melhorias nas ações e reformulações relacionadas às políticas públicas e à gestão das instituições parcerias nesse programa, assim como tem [re]pensado e [re]articulado seus processos formativos a partir das novas demandas e desafios educacionais na atualidade.

\section{Programa Observatório da Educação}

Desde 2013, o Grupo de Pesquisa Elos/CNPq é responsável pela operacionalização de um projeto local do Programa Observatório da Educação (OBEDUC), financiado pela Coordenação de Aperfeiçoamento de Pessoal de Nível Superior - CAPES/Brasil (BR). O projeto OBEDUC/Elos, intitulado "Interlocuções entre Educação Básica e a Educação Superior: limites e possibilidades das políticas públicas e ações pedagógicas", tem como eixos temáticos a educação básica e a educação superior, com as seguintes áreas de investigação: ensino médio; educação e ação pedagógica; avaliação institucional e da aprendizagem e políticas públicas educacionais.

Essas dimensões e problematizações estão imbricadas na conjuntura de análises e estudos do grupo Elos, articulando projetos de pesquisa individuais e coletivos, inseridos na interlocução entre os eixos da educação básica e o ensino superior e quatro frentes de investigação, sendo estas a tratar da: 1) Identificação dos processos que envolvem as políticas públicas nacionais e suas relações com a nova proposta do governo do Estado do Rio Grande do Sul, denominada "Proposta Pedagógica para Ensino Médio Politênico e Educação Profissional Integrada ao Ensino Médio - 2011-2014”, destacando os impasses e desafios encontrados por professores de Escolas Estaduais de Educação Básica para a implementação curricular; 2) Compreensão sobre as influências da avaliação promovida pelo Sistema Nacional de Avaliação da Educação Superior (SINAES) na construção curricular do Curso de Pedagogia da UFSM, considerando o impacto na ação pedagógica dos egressos nas escolas públicas de Educação Infantil do município de Santa Maria; 3) Análise das políticas públicas que instituiu o sistema Universidade Aberta do Brasil (UAB) de forma a identificar em que medida suas ações estão relacionadas à expansão e consolidação da EAD no ensino superior público, considerando os egressos do curso de Pedagogia da UFSM dos polos da AMcentro; 4) Delineamento e analise sobre os limites e as possibilidades dos Conselhos Municipais de Educação, vinculados ao Pró-Conselho no Rio Grande do Sul na Região de abrangência da AMcentro, considerando a existência de Sistema, tempo de atuação, configuração dos CMEs, financiamento, proposições de políticas públicas, ações desenvolvidas junto as Mantenedoras e Escolas públicas, orientações para a [re] construção dos Projetos Político-Pedagógicos das Escolas Públicas, marcos regulatórios, formação dos Conselheiros entre outros aspectos subjacentes ao perfil e atuação dos Conselheiros. 
Essas áreas de investigação dimensionam a transversalidade da pesquisa em educação e o papel que cada sujeito partícipe assume, bem como, a forma que se constituem pesquisadores do Observatório da Educação (OBEDUC). Nessa perspectiva, o OBEDUC de acordo com a página da CAPES é:

[...] resultado da parceria entre a Capes, o INEP e a SECADI, foi instituído pelo Decreto Presidencial $n^{\circ} 5.803$, de 08 de junho de 2006, com o objetivo de fomentar estudos e pesquisas em educação, que utilizem a infra-estrutura disponível das Instituições de Educação Superior - IES e as bases de dados existentes no INEP. O programa visa, principalmente, proporcionar a articulação entre pósgraduação, licenciaturas e escolas de educação básica e estimular a produção acadêmica e a formação de recursos pós-graduados, em nível de mestrado e doutorado. (BRASIL, 2015)

Com base neste objetivo, o grupo de pesquisa Elos, concorreu ao edital de 2012 e teve seu projeto aprovado. A interlocução com a educação básica e superior, como pode ser visto nos objetivos do projeto apresentado, é o ponto nevrálgico das pesquisas desenvolvidas. Atualmente, contamos com a participação de um bolsista de doutorado, três de mestrado, seis de graduação e seis da educação básica, além dos demais pesquisadores colaboradores, todos envolvidos em pesquisas vinculadas à articulação entre a educação básica e superior. $\mathrm{O}$ diálogo entre os docentes na prática e os acadêmicos na instituição tem promovido um crescimento tanto acadêmico, quanto profissional a todos os envolvidos, possibilitando a produção de conhecimento, é preciso considerar o contexto pesquisado na sua complexidade, tendo como base anterior a qualquer método de pesquisa, o conhecimento dos aspectos sociais, históricos e culturais do objeto que se pretende pesquisar.

Inicialmente o projeto pretendia atingir um número de 20 produtos ao final dos quatro anos, porém destaca-se que os bolsistas, pesquisadores e colaboradores tem produzido mais do esta meta por ano. Enfatiza-se que tais produções não possuem caráter "produtivista", mas refletem o compromisso de todos os envolvidos com processos de pesquisa em íntima interlocução entre educação básica e superior. A articulação entre a educação básica e superior tem se caracterizado como uma estratégia de trabalho, a participação dos profissionais da educação básica tem possibilitado um diálogo permanente e a inserção dos pesquisadores/acadêmicos, tem aberto o espaço para divulgar os resultados encontrados e dar visibilidade a uma realidade que transcendem os dados do INEP, eles tem ganhado significado no contexto das pesquisas desenvolvidas.

\section{Programa Nacional de Capacitação de Conselheiros Municipais de Educação}

O Programa Nacional de Capacitação de Conselheiros Municipais de Educação (PróConselho) instituído pela Secretaria de Educação Básica do Ministério da Educação (SEB/MEC), através da Portaria Ministerial $n^{\circ} 3.272$, de 6 de novembro de 2003, tem o intuito de fomentar a participação e a formação da sociedade nos aspectos referentes a estrutura organizacional dos Conselhos Municipais de Educação no que tange à fiscalização, normatização, consulta, deliberação e mobilização democrática de gestão educacional nos diferentes municípios dos Estados brasileiros (BRASIL, 2009).

Destaca-se que a política de democratização no Brasil, desenvolvida pelo PróConselho, potencializa a formação continuada de conselheiros de educação, o que repercute

\begin{tabular}{l|l|l|l|l|l|l} 
() Rev. Inter. Educ. Sup. & Campinas, SP & v.1 & n.2 & p.160-181 & out./dez. 2015 & ISSN 2446-9424
\end{tabular}


no fortalecimento da gestão democrática dos sistemas municipais de ensino (BATISTA, 2013). Nessa ótica, as Universidades Federais são as gestoras desse Programa em nível nacional e estadual e, nesse sentido, estabelecem regime de cooperação técnica com a SEB/MEC, a União Nacional dos Conselhos Municipais de Educação (UNCME) e com a União Nacional dos Dirigentes Municipais de Educação (UNDIME), para a consecução da política nacional de formação dos Conselheiros Municipais de Educação. Para tanto, cada estado constitui o seu próprio grupo de trabalho (GT Estadual) a partir da cooperação e articulação destes órgãos e Universidades.

Alinhadas aos preceitos do Pró-Conselho nacional as Instituições de Ensino Superior (IES) constroem e registram projetos voltados para o desenvolvimento de ações extensionistas trabalhadas de maneira processual e interdependentes, cujas temáticas são consideradas de interesse para o desenvolvimento profissional do Conselheiro e do Técnico, estão voltadas para potencializar apoio teórico-prático que fundamenta as atividades dos Conselhos Municipais de Educação. O Curso de Formação Continuada de Conselheiros Municipais de Educação, desenvolvido na Universidade Federal de Santa Maria no estado do Rio Grande do Sul (Pró-Conselho/UFSM), objetiva de maneira geral a capacitação de Conselheiros Municipais de Educação e/ou Técnicos das Secretarias Municipais de Educação do RS, no sentido de qualificar a atuação dos mesmos e os Conselhos Municipais de Educação instância efetiva de proposição, fiscalização e normatização das políticas e gestão da educação municipal. Tais processos formativos são fomentados pela Secretaria de Educação Básica (SEB/MEC) na perspectiva de desencadear a [re]construção do conhecimento, saberes e fazeres pelos Conselheiros de Educação e Técnicos de Secretarias de Educação e contribuir para o fortalecimento e a criação de novos CME no Brasil.

O Programa, em especial, contribui para a formação continuada de conselheiros, na criação e fortalecimento de novos Conselhos Municipais de Educação. A partir dos processos inter-relacionados à formação continuada torna-se possível a [re]significação de aspectos teóricos e práticos, no sentido de superar a ação fragmentada, visando a interação entre os aspectos conceituais, procedimentais e atitudinais oriundos do conhecimento da profissão/função traduzidos em saberes do conhecimento, saberes da ação pedagógica e saberes experienciais (GAUTHIER, 1998). A formação permanente precisa ser pensada como um investimento para a transformação no exercício da profissão/função, destacando o papel importante não apenas do Conselheiro ou Técnico de Educação em seu grupo de pares, como também o papel deste grupo na construção cotidiana de uma nova cultura no contexto da gestão da educação municipal.

O Curso de Formação Continuada de Conselheiros Municipais de Educação ocorre na modalidade à distância, via ambiente virtual de aprendizagem, por meio do ambiente Moodle Conselheiros. A estrutura curricular do curso está intimamente articulada com base nas orientações expressas no Guia de Diretrizes do Programa: “[...] estrutura curricular modular; formação com base em diferentes materiais didáticos e ênfase na continuidade da formação dos conselheiros" (BRASIL, 2009, p. 11). Assim, a organização curricular foi definida em cinco módulos temáticos distribuídos em 164 horas à distância e 16 horas presenciais.

O Pró-Conselho, como mecanismo de consecução das políticas públicas de formação e desenvolvimento profissional e de democratização da gestão educacional, permite uma visão mais aprofundada acerca dos marcos legais que organizam o sistema educacional brasileiro. Para tanto, o ambiente do curso que está dividido em módulos com diferentes

\begin{tabular}{l|l|l|l|l|l|l} 
(C) Rev. Inter. Educ. Sup. & Campinas, SP & v.1 & n.2 & p.160-181 & out./dez. 2015 & ISSN 2446-9424
\end{tabular}


abordagens (Módulo 1 - Educação e Tecnologia; Módulo 2 Princípios, Estrutura e Funcionamento do CME; Módulo 3 - Subsídios para Atuação do Conselheiro; Módulo 4 Conselho Municipal e as Políticas Públicas; e o Módulo 5 - Projeto Integrador), está articulado, justamente, para instrumentalizar e capacitar os conselheiros e técnicos partícipes desse processo de fortalecimento dos CME no Brasil (BRASIL, 2009). Apesar do conteúdo ser organizado em estrutura modular, os módulos são complementares e dão subsídios teóricos e práticos para a elaboração do Projeto Integrador ao final do curso, tendo como ponto de partida e chegada o contexto da educação municipal de cada integrante do curso.

Para a consecução do Curso de Formação Continuada de Conselheiros Municipais de Educação, gestado pela UFSM, buscou-se constituir o grupo de trabalho do Estado do Rio Grande do Sul (GT Estadual RS) a partir da cooperação e articulação com a UNCME/RS, a UNDIME/RS, as Secretarias Municipais de Educação do RS e a Universidade Federal de Santa Maria (UFSM). A Cooperação ficou acordada a partir do planejamento compartilhado do Projeto de Extensão e respectivo Plano de Ação do Curso de Formação Continuada de Conselheiros Municipais de Educação pelo GT Estadual RS, considerando a execução conjunta de ações de formação dos Conselheiros/Técnicos no ensino a distância e em encontros/oficinas presenciais.

Assim sendo, atualmente, a organização e constituição das equipes pedagógica e técnica do Pró-Conselho/UFSM, concretiza-se pelo trabalho desenvolvido por bolsistas: uma coordenação geral (um professor do quadro de docentes da instituição), um coordenador adjunto pedagógico, um coordenador local (indicado pela UNCME/RS), seis professores formadores, três tutores, um apoio administrativo e um apoio técnico em informática.

A $1^{\text {a }}$ edição do Pró-Conselho/UFSM, que tinha como meta de capacitação 120 cursistas, foi desenvolvida no período de abril a setembro de 2013. Sendo assim, a matrícula inicial atingiu um total de 156 cursistas representantes de 78 municípios do Estado do Rio Grande do Sul, resultando num total de 131 conselheiros de educação e técnicos de secretarias aprovados ao final do curso, 18 evasões e 7 reprovações. A $2^{\text {a }}$ edição do PróConselho/UFSM, dividida em duas ofertas, que tinha como meta de capacitação 320 cursistas, foi realizada nos períodos de outubro de 2013 a abril de 2014 ( $1^{\mathrm{a}}$ oferta) e de maio a novembro de 2014 ( $2^{\mathrm{a}}$ oferta). Na $1^{\mathrm{a}}$ oferta dessa edição do curso foram matriculados cerca de 192 cursistas e respectivos 98 municípios, na $2^{\mathrm{a}}$ oferta foram matriculados 198 cursistas e respectivos 103 municípios, totalizando 390 cursistas matriculados inicialmente e 178 municípios envolvidos. Os indicadores de finalização dessa edição do curso sinalizam 298 aprovados, 76 evadidos e 16 reprovados. A $3^{\text {a }}$ edição do Pró-Conselho/UFSM, que tinha como meta de capacitação 180 cursistas, iniciou as atividades em abril e finalizou em novembro de 2015, com uma matrícula inicial de 222 cursistas representantes de 98 municípios. Os indicadores de finalização dessa edição do curso sinalizam 172 aprovados, 47 evadidos e 3 reprovados.

O Pró-Conselho objetiva, especialmente, aproximar as distâncias e consolidar parcerias entre a Universidade, a UNCME/RS, a UNDIME/RS e Municípios envolvidos, no sentido de [re]construir conhecimentos significativos ao âmbito das políticas públicas para a educação municipal e contribuir para os processos de democratização da gestão educacional e escolar. Se, por um lado, os conselheiros e técnicos de secretarias municipais de educação sentem-se apoiados e valorizados pelo desenvolvimento do Programa, que e desenvolvido pelas IES pelo viés extensionista, por outro, na universidade passou a olhar mais de perto e

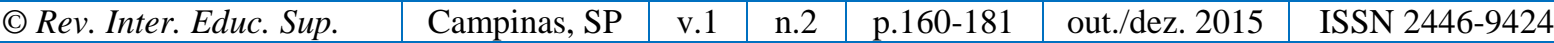


com propriedade as demandas das políticas públicas e gestão educacional no sentido de relacionar teoria e prática como elemento norteador aos processos de formação e atuação dos gestores que atuam na educação básica. Assim sendo, o desenvolvimento das ações extensionistas, estiveram e estão focadas na qualificação, cada vez maior, da parceria da Universidade Federal de Santa Maria com a sociedade, na perspectiva de oportunizar ações e estudos de efetiva melhoria da produção do conhecimento na gestão educacional, especialmente nas respectivas redes e/ou sistemas de ensino envolvidos.

Considerando que o curso consolida seus processos formativos, em sua maioria, na modalidade a distância, em ambiente Moodle, a utilização de tecnologias digitais no processo de ensino e de aprendizagem virtual, assim como na produção científica, tem se apresentado como um desafio para as instituições de ensino superior, mas, também, aos cursistas que se lançam nesta modalidade educativa com a expectativa de formação e qualificação. Nessa perspectiva, a utilização do ambiente virtual de aprendizagem tem se caracterizado como diferencial, justamente, porque se constitui organizado para inserção, estudo e interlocução dos participantes com conteúdos e recursos disponibilizados virtualmente, assim como para contato com outros envolvidos nos processos formativos.

Entende-se que os objetivos do projeto estão sendo atingidos, uma vez que os impactos das ações de extensão via curso de formação continuada, estão promovendo maior comprometimento da comunidade universitária com interesses e necessidades da sociedade, em especial dos Conselhos Municipais de Educação do RS, assim como o desenvolvimento municipal e regional na criação de novos Conselhos Municipais de Educação, reativação ou rearticulação dos Conselhos de Educação existentes, criação ou fortalecimento de Sistemas Municipais de Ensino e, sobretudo, a [re]significação das funções e atuação do conselheiros de educação em tais órgãos colegiados.

\section{CONSIDERAÇÕES TRANSITÓRIAS}

As considerações finais, sempre transitórias, pois se tratam de programas que, todavia não foram finalizados e de uma dimensão que não tem fim, sempre cíclica e em permanente movimento. Assim, é importante revisitar nessas considerações o objetivo deste estudo voltado para "analisar os impactos das políticas de formação inicial e permanente nos cursos de licenciaturas da Universidade Federal de Santa Maria a repercussão em contextos emergentes na educação superior".

Os programas aqui analisados - PIBID, OBEDUC e PRÓ-CONSELHO, colocam em ação políticas públicas educacionais propostas pelo governo federal, a partir dos contextos educacionais das instituições escolares brasileiras, que repercutem na articulação entre a educação básica e superior, condição necessária e indispensável para qualificar a educação brasileira. Não é possível que as discussões realizadas no âmbito das universidades não dialoguem com o cotidiano das escolas e, consequentemente, nas práticas escolares.

A participação das universidades em programas, com a natureza dos aqui estudados (ensino, pesquisa e extensão), promove e desafia ao comprometimento e atualização

\begin{tabular}{l|l|l|l|l|l|l} 
(C) Rev. Inter. Educ. Sup. & Campinas, SP & v.1 & n.2 & p.160-181 & out./dez. 2015 & ISSN 2446-9424
\end{tabular}


constante dos docentes universitários com a formação inicial e permanente dos profissionais que atuam na educação, sejam os acadêmicos, futuros docentes, sejam com os já os profissionais em serviço como professores e conselheiros municipais da educação.

Promover a articulação entre a educação básica e superior é uma premissa que está presente nas políticas públicas educacionais, que estão inseridas no movimento mundial que preconiza a internacionalização dos objetivos educacionais, através das políticas propostas pelos organismos internacionais, que exigem dos profissionais da educação, que atuam em espaços educacionais, seja em funções de regência ou de gestão, estar articulados permanentemente para alcançarmos os objetivos fins da educação.

Então, a partir da concepção de contextos emergentes, compreende-se que se referem a novos desafios e, nesse sentido, que demandam novos posicionamentos e ações de gestão político-pedagógica na educação superior. De acordo com Juliatto (2005, p. 19-20):

\begin{abstract}
Cresce no Brasil a preocupação com a qualidade da educação superior [...] A preocupação demonstra que se vê inadiável a necessidade de melhoramento imediato, o que demanda critério, proficiência e, mais que tudo, determinação e constância. [...] A preocupação com a qualidade da educação superior não ocorre apenas no Brasil. Ela existe como crescente desafio mundial.
\end{abstract}

A exemplo do que dimensiona o autor, verifica-se na consecução das políticas educacionais, por meio de programas de governo, a preocupação com a melhoria da qualidade da educação, considerando que nas últimas décadas no mundo inteiro está acontecendo um movimento de internacionalização na educação superior que, consequentemente, está envolvido com a [re]articulação da universidade nesse cenário entendendo-a como pilar para a formação e atuação profissional.

Assim sendo, no Brasil as Instituições de Educação Superior, a partir da cooperação técnica com os entes federados entre outras instituições educacionais, passaram a reconhecer novos contextos de interatuação e, nesse sentido, a contribuir para melhorias nas ações e reformulações relacionadas às políticas públicas e à gestão da educação. Certamente, tais ações de ensino, pesquisa e extensão, mediatizadas por programas de governo desenvolvidos e/ou gestionados pelas Instituições de Educação Superior, ampliam as possibilidade de [re]construção, sistematização e socialização do conhecimento teórico-prático na área das políticas públicas e gestão educacional para todos os sujeitos e contextos envolvidos. 


\section{REFERÊNCIAS}

ANDRÉ, M. E. Etnografia e prática escolar. Campinas: Papirus, 1995.

AZEVEDO, M. N.; CATANI, A. M. Educação superior, internacionalização e circulação de ideias: ajustando os termos e desfazendo mitos. INTER-AÇÃO, Goiânia, v. 38, n. 2, p. 273291, 2013.

BATISTA, N. C. Políticas públicas para a gestão democrática da educação básica: um estudo do Programa Nacional de Formação de Conselheiros Municipais de Educação. Jundiaí: Pacto Editorial, 2013.

BRASIL. Lei $\mathbf{n}^{\mathbf{0}}$ 9.394, de 20 de dezembro de 1996. Estabelece as diretrizes e bases da educação nacional. Diário Oficial da União, Brasília, 1996.

BRASIL. Ministério da Educação. Guia de diretrizes. Programa de Formação de Conselheiros Municipais de Educação - Pró-Conselho. Brasília: Secretaria de Educação Básica; Universidade Federal de Santa Catarina, 2009.

Resolução CNE/CP no 1, de 18 de fevereiro de 2002. Institui Diretrizes

Curriculares Nacionais para a formação de professores da educação básica, em nível superior, curso de licenciatura de graduação plena. Brasília/DF, 2002. Disponível em:

<http://portal.mec.gov.br/seesp/arquivos/pdf/res1_2.pdf>. Acesso em: 10 abr 2014.

\section{FUNDAÇÃO CAPES. MINISTÉRIO DA EDUCAÇÃO. Observatório da}

educação. Disponível em: < http://www.capes.gov.br/educacao-basica/observatorio-daeducacao $>$. Acesso em: 18 dez. 2015.

BRASIL, Ministério da Educação. Portaria Normativa nº 38, de 12 de dezembro de 2007 Dispõe sobre o Programa de Bolsa Institucional de Iniciação à Docência - PIBID. Diário Oficial da União, Brasília, 2007. Disponível em:

<https://www.capes.gov.br/images/stories/download/legislacao/Portaria_Normativa_38_PIBID.pdf>. Acesso em: 15 jun. 2015.

Ministério da Educação. Secretaria de Educação Básica. Rede Nacional de

Formação Continuada de Professores de Educação Básica: orientações gerais, 2008. Catálogo. Disponível em: 〈http://portal.mec.gov.br/dmdocuments/catalogo2008azul.pdf〉. Acesso em: 10 abr 2014.

Decreto $\mathbf{n}^{\mathbf{0}} \mathbf{5 . 6 2 2}$, de 19 de dezembro de 2005. Regulamenta o artigo 80 da Lei $\mathrm{n}^{\circ}$ 9.394 de 20 de dezembro de 1996 que estabelece as Diretrizes e Bases da Educação Nacional. Educação a Distância. Brasília/DF, 2005.

Decreto no 5.800, de 8 de junho de 2006. Dispõe sobre o Sistema Universidade Aberta do Brasil - UAB. Brasília/DF, 2006.

Decreto no 6.096, de 24 de abril de 2007. Institui o Programa de Apoio a Planos de Reestruturação e Expansão das Universidades Federais - REUNI. Disponível em: <http://www.planalto.gov.br/ccivil_03/_ato2007-2010/2007/decreto/d6096.htm>. Acesso em: 10 abr 2014. 
Decreto no 6.755, de 29 de janeiro de 2009. Institui a Política Nacional de Formação de Profissionais do Magistério da Educação Básica, disciplina a atuação da Coordenação de Aperfeiçoamento de Pessoal de Nível Superior - CAPES.

Decreto no 7.219, de 24 de junho de 2010. Dispõe sobre o Programa Institucional de Bolsa de Iniciação à Docência - PIBID e dá outras providências. Brasília/DF, 2010.

BRASIL, Ministério da Educação. Portaria no 096, de 18 de Julho de 2013. Disponível em: <http://www.capes.gov.br/images/stories/download/legislacao/Portaria_096_18jul13_AprovaRegula mentoPIBID.pdf>. Acesso em: 8 jun. 2015.

Resolução CNE/CP no 1 , de $1^{\circ}$ de julho de 2015. Institui Diretrizes Curriculares Nacionais para a formação inicial em nível superior (cursos de licenciatura, cursos de formação pedagógica para graduados e cursos de segunda licenciatura) e para a formação continuada. Disponível em: <http://ced.ufsc.br/files/2015/07/RES-2-2015-CP-CNEDiretrizes-Curriculares-Nacionais-para-a-forma\%C3\%A7\%C3\%A3o-inicial-emn\%C3\%ADvel-superior.pdf>. Acesso em: 19 jun 2015.

CASTRO, M. H. G. A educação para o século XXI: o desafio da qualidade e da eqüidade. Brasília: Instituto Nacional de Estudos e Pesquisas Educacionais, 1999. Encontrada em: <http://www.publicacoes.inep.gov.br/arquivos/\{D5A1303D-6BD9-4DD6-AA3A 66FF8E5B2C29\}_Educacaoseculo21.pdf>. Acesso em: 20 mar 2010.

DECLARAÇÃO MUNDIAL SOBRE EDUCAÇÃO SUPERIOR NO SÉCULO XXI: Visão e Ação. Paris, 9 de outubro de 1998. Disponível em: $<$ http://www.scribd.com/doc/9715944/Declaracao-Mundial-Sobre-Educacao-Superior-No Seculo-XXI>. Acesso em: 15 mai 2014.

FEREIRA, S.; OLIVEIRA, J. F. As reformas da educação superior no Brasil e na união europeia e os novos papeis das universidades públicas. Nuances: estudos sobre Educação, v.17, n.18, p.50-67, jan./dez., 2010.

GATTI, B. A.; BARRETO, E. S. de S. (Org.). Professores do Brasil: impasses e desafios. Brasília: UNESCO, 2009. 294 p.

GAUTHIER, C. et al. Por uma teoria da pedagogia: pesquisas contemporâneas sobre o saber docente. RS. Ijuí : Ed. UNIJUÍ, 1998.

GOMES, C.; FELÍCIO, H. M. S.(Org.). Caminhos para a docência: o PIBID em foco. São Leopoldo: Oikos, 2012.

GUNI. International Barcelona Conference. 2008. Disponível em: <http://www.gunirmies.

IESALC. O Instituto Internacional para a Educação Superior na América Latina e no Caribe - IESALC. UNESCO. Disponível em: <http://www.iesalc.unesco.org>. Acesso em: 20 out 2015.

JULIATTO, C. I. A Universidade em busca da excelência: um estatuto sobre a qualidade da educação. 2.ed. Curitiba: Chapagnat: Goiânia: Ed. Da UCG, 2005. 
MEC/CAPES. Programa de Consolidação das Licenciaturas. Disponível em: < http://www.capes.gov.br/educacao-basica/prodocencia>. Acesso em: 15 maio 2014

MOROSINI, M. C. O Ensino Superior no Brasil. In.: STEPHANOU, Maria; BASTOS, Maria Helena Câmara. Histórias e Memórias da Educação no Brasil. Petrópolis, RJ: Vozes, 2005, p. 296-323. v.3.

Qualidade da educação superior e contextos emergentes. Avaliação, Campinas; Sorocaba, SP, v. 19, n. 2, p. 385-405, jul. 2014

OECD. Organização para a Cooperação Econômica e Desenvolvimento. Disponível em: <http://www.oecd.org>. Acesso em: 12 abr 2010.

SCHEIBE, L.; BAZZO, V. L. Diretrizes Curriculares Nacionais para os Cursos de Licenciatura no Brasil: da regulamentação aos Projetos Institucionais. Educação em Perspectiva, Viçosa, v. 4, n. 1, p. 15-36, jan./jun. 2013. Disponível em: < http://www.seer.ufv.br/seer/educacaoemperspectiva/index.php/ppgeufv/article/viewFile/420/ 100>. Acesso em: 20 out 2015.

TOMAZETTI, E. M.; LOPES, A. V. (Org.). PIBID-UFSM: experiências e aprendizagens. São Leopoldo: Oikos, 2013. v. 2.

TRIVIÑOS, A. N. S. Introdução à pesquisa em ciências sociais: a pesquisa qualitativa em educação. São Paulo: Atlas, 2008.

UNESCO. Organização das Nações Unidas para a Educação, a Ciência e a Cultura. Disponível em: <http://www.unesco.org/new/pt/brasilia/>. Acesso em: 15 mai 2010.

YIN, R. Estudo de Caso: Planejamento e métodos. Porto Alegre: BooKman, 2005. 